\title{
Acute Appendicitis after Liver Transplant: A Case Report and Review of the Literature
}

\author{
Ronaldo de Oliveira Andrade, Rodrigo da Silva Pires, Raul Évora Silva, \\ Felipe Pedreira Tavares de Mello, Cláudia Cristina Tavares de Sousa, \\ Samanta Teixeira Basto, Eduardo de Souza Martins Fernandes \\ Department of Surgery and Liver Transplant, Hospital Adventista Silvestre, Rio de Janeiro, Brazil \\ Email: esmfernandes@hotmail.com
}

Received 29 September 2014; revised 29 October 2014; accepted 17 November 2014

Copyright (C) 2014 by authors and Scientific Research Publishing Inc.

This work is licensed under the Creative Commons Attribution International License (CC BY). http://creativecommons.org/licenses/by/4.0/

(c) † Open Access

\begin{abstract}
Acute appendicitis is rare in the postoperative period of liver transplantation; only 23 cases were described in the literature to date, including late and immediate postoperative. Our case reports a patient who was presented with acute appendicitis in the immediate post-transplant and died in the subsequent postoperative period. The article reviews the available literature and all cases known until now, commenting on incidence, casual factors, symptoms, diagnostic and management.
\end{abstract}

\section{Keywords}

\section{Appendicitis, Complications, Early Postoperative, Liver Transplantation}

\section{Introduction}

Acute appendicitis is the most common surgical emergency around the world and in a study conducted in 2012 in Pennsylvania, USA, there was an increase in the annual incidence from 7.62 to 9.38 per 10,000 between 1993 and 2008 [1]. However, in the postoperative period of solid organ transplantation appendicitis is rare, and only 22 cases (one being a child)[2] occurring in the post-liver transplantation have been reported in the literature so far.

\section{Case Report}

Male patient aged 43, native from Rio de Janeiro, Brazil, carrier secondary biliary cirrhosis (SBC) by sclerosing cholangitis (SC) and history of ulcerative colitis (UC), taking prednisone, received cadaveric donor liver transplant performed on 03/03/2012 without complication or need for blood transfusion. He was discharged from the ICU on third postoperative day with oral diet, liver function test demonstrating good graft function, leukocytes 9350 with $8 \%$ bands and reactive C protein (RCP) $6.5 \mathrm{mg} / \mathrm{dL}$ and using of tacrolimus. On the fifth postoperative day presented diarrhea, abdominal distention and abdominal tenderness and pain in the lower deck, as well as worsening of laboratory parameters (leucopenia 3350 with $15 \%$ bands and RCP 31.2). There were no signs of 
peritoneal irritation or palpable masses, or had, on occasion, fever, nausea or vomiting. Abdominal CT scan reveals non-specific result and changes compatible with the surgery. He showed leukocytosis with a left shift (12.060 leukocytes with $16 \%$ bands) only on the seventh postoperative day, in the presence of empirical antibiotic therapy with fluconazole and meropem. On the twelfth day presented moderate fever and drainage of purulent discharge from surgical wound, being observed aponeurosis dehiscence and contained evisceration, opting for laparotomy observing acute appendicitis with peritonitis.

Appendicectomy and drainage of abscesses in the abdominal cavity were performed by bi-subcostal previous incision. The patient had multiple complications and required other laparotomies for cavity wash, pancreatic necrosectomy and external drainage of the bile duct due to hepaticojejuno anastomosis dehiscence. Unfortunately, he died in the fourth postoperative day of liver transplantation from fungal sepsis growth if Candidiaparapsilosis in culture fluid of the abdominal cavity.

\section{Discussion}

A literature review shows that the acute appendicitis after liver transplantation (AALT) is rare, with an incidence ranging from $0.09 \%$ to $0.49 \%$ [3], and that a number of 3 cases was the highest reported in the same service until now [4]. In our service of Hospital Adventista Silvestre in Rio de Janeiro, Brazil, 150 liver transplants were performed between August 2010 and December 2013, and only one developed acute appendicitis, with gives us an incidence of $0.67 \%$. However, to date, there were no deaths from AALT, this being the first case report, and therefore we can say that the global lethality rate for this type of appendicitis goes from zero to $4.35 \%$.

Nevertheless, due to the increase in the number of transplant cases, improving techniques and medications, as well as the survival of these patients, the case numbers of AAKT, tends to increase, since the first report in 2005. As occurs in nonimmunocompromised patients, it is believed that the etiology of appendicitis in transplanted patients involves the obstruction of the lumen of the appendix (or lymphnode hypertrophy) and bacterial overgrowth, resulting in an increase of intraluminal pressure [3] [4] and restricting blood flow to the region. There are reports that infection with cytomegalovirus (CMV) increases the incidence of acute appendicitis [3] [4], due to the predilection of the virus to the lymphoid organ, which cause hyperplasia of the appendix.

The postoperative diagnosis can be a challenge, since some patients leave from surgery under intensive care, and clinical and laboratory parameters can still be altered due to the endocrine metabolic response to trauma, such as lekocytosis and increased RCP, and abdominal pain diffuse. Moreover, due to the complex inflammatory response in immunosuppressed, the diagnosis can be confused with graft-related complications in the immediate postoperative period [3]. The clinical findings do not differ from common acute appendicitis, and may occur: diffuse abdominal pain, fixed tenderness in the right iliac fosse with or without rebound tenderness, fever, nausea, vomiting and diarrhea [2]-[7]. The laboratory may have leukocytosis, but six of these patients (26\%) did not [2] [4]. Imaging tests are extremely useful in such cases. Abdominal ultrasound can confirm the diagnosis and has good accuracy if performed by an experience physician [3] [5]. Computed tomography has been describe as a method of choice, but despite not being an examiner-dependent method, if performed by a scanner of low sensibility, may result in delayed diagnosis and surgical treatment, as occurred in our case.

The different diagnosis is difficult and must include perforation of intestinal loops, biliary fistula, graft-related complications, such as infection, rejection and thrombosis [3]. There is also a high incidence of perforation of the appendix in the reported cases especially after three days of evolution [4] [5]. In our case, the patient was diagnosed with ulcerative colitis, winch made us think he might be having a recurrence of the disease, since the image in examination was nonspecific.

Therefore, surgical treatment should be implemented as soon as possible. Conventional incision for appendectomy or laparotomy for cases of diagnostic uncertainty may be performed. There is also one reported case of laparoscopic appendectomy, but the patient in question was in the late postoperative period (two years), being described as a method that can be performed in selected cases[5].

\section{Conclusion}

Despite the clinical presentation similar to common appendicitis, the diagnosis of acute appendicitis after liver transplantation is not simple, especially in the immediate postoperative period, as in the case described (Figure 1). Additional tests in the majority of the cases help to confirm the diagnosis. However, in our experience, the 


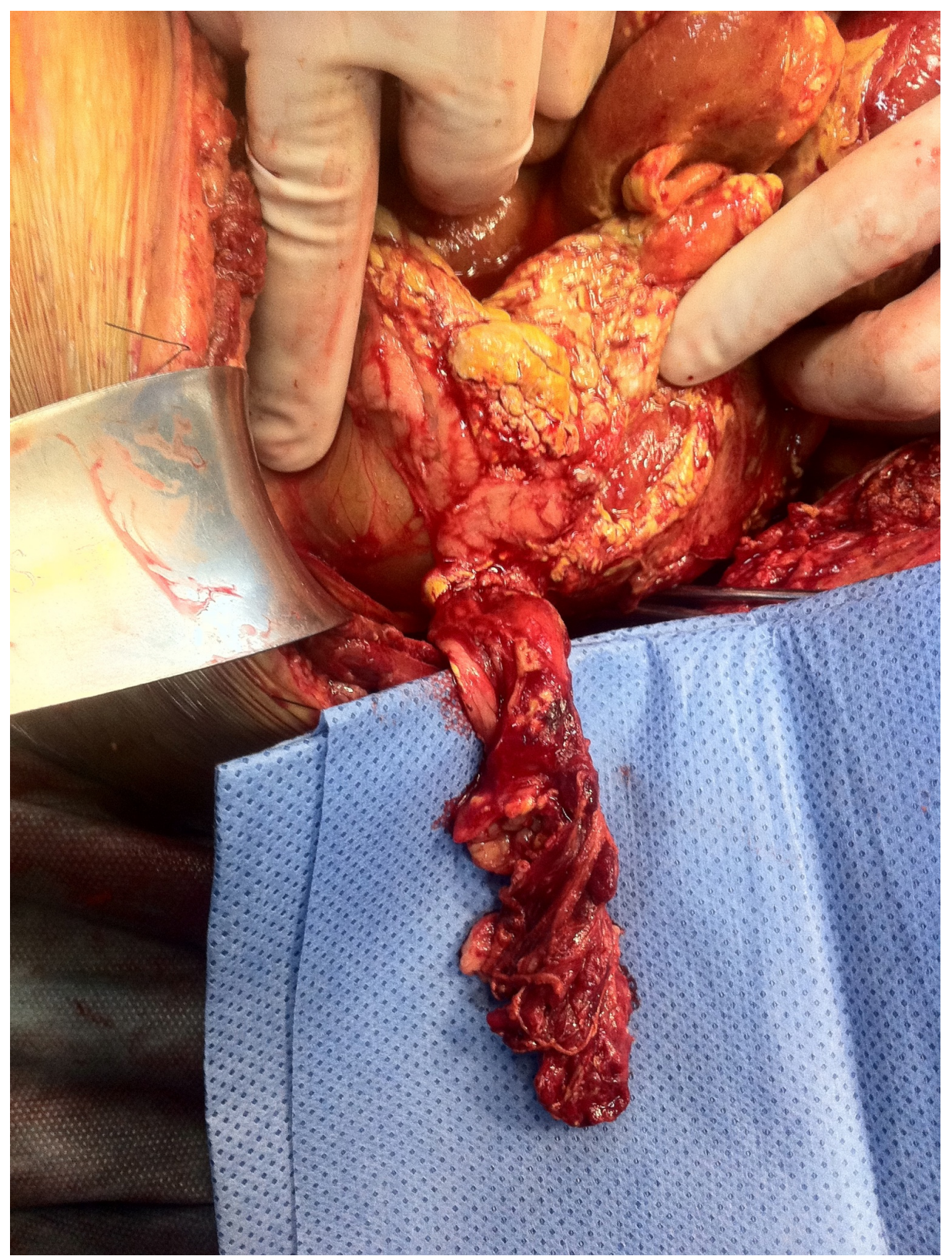

Figure 1. Appendix.

CT scan could have changed the outcome of the case if it had detected the disease early. Thus suspicion and clinical diagnosis are the greatest weapons against acute appendicitis.

\section{References}

[1] Buckius, M.T., McGrath, B., Moonk, J., Grim, R., Bell, T. and Ahuja, V. (2012) Changing Epidemiology of Acute Appendicitis in the United States: Study Period 1993-2008. Journal of Surgical Research, 175, 185-190. http://dx.doi.org/10.1016/j.jss.2011.07.017

[2] Aktas, S., Sevmis, S., Karakayali, H., Ozcay, F., Coskun, M., Bilezikci, B. and Haberal, M. (2011) Acute Appendicitis after Diaphragmatic hernia after Pediatric Liver Transplant. Experimental and Clinical Transplantation, 9, 63-67.

[3] Wu, L.W., Zhang, J.W., Guo, Z.Y., Tai, Q., He, X.S., Lu, W.Q., Wang, D.P. and Zhu, X.F. (2011) Diagnosis and Treatment of Acute Appendicits after Orthopic Liver Transplant in Adults. Experimental and Clinical Transplantation, 9, 113-117. 
[4] Abt, P.L., Abdullah, I., Korenda, K., Frank, A., Peterman, H., Stephenson, G.R., Markmann, J.F., Shaked, A. and Olthoff, K.M. (2005) Appendicitis among Liver Transplant Recipients. Liver Transplantation, 11, 1282-1284. http://dx.doi.org/10.1002/lt.20568

[5] Quartey, B., Dunne, J. and Cryer, C. (2012) Acute Appendicitis Post Liver Transplant: A Case Report and Literature Review. Experimental and Clinical Transplantation, 10, 183-185. http://dx.doi.org/10.6002/ect.2011.0124

[6] Ceulernans, P., Wybaillie, E., Monbaliu, D., Aerts, R. and Pirenne, J. (2010) Acute Appendicitis after Liver Transplantation: A Case Report and Review of the Literature. Acta Chirurgica Belgica, 110, 335-338.

[7] Savar, A., Hiatt, J.R. and Busuttil, R.W. (2006) Acute Appendicitis after Solid Organ Transplatation. Clinical Transplantation, 20, 78-80. http://dx.doi.org/10.1111/j.1399-0012.2005.00444.x 
Scientific Research Publishing (SCIRP) is one of the largest Open Access journal publishers. It is currently publishing more than 200 open access, online, peer-reviewed journals covering a wide range of academic disciplines. SCIRP serves the worldwide academic communities and contributes to the progress and application of science with its publication.

Other selected journals from SCIRP are listed as below. Submit your manuscript to us via either submit@scirp.org or Online Submission Portal.
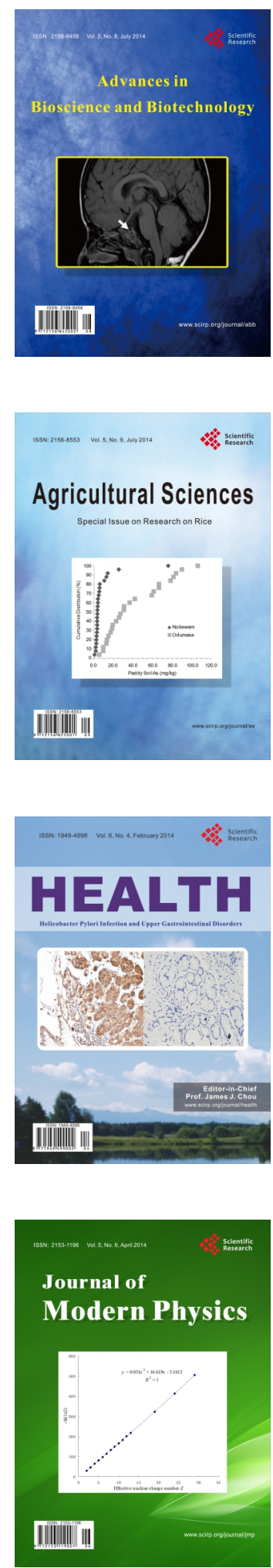
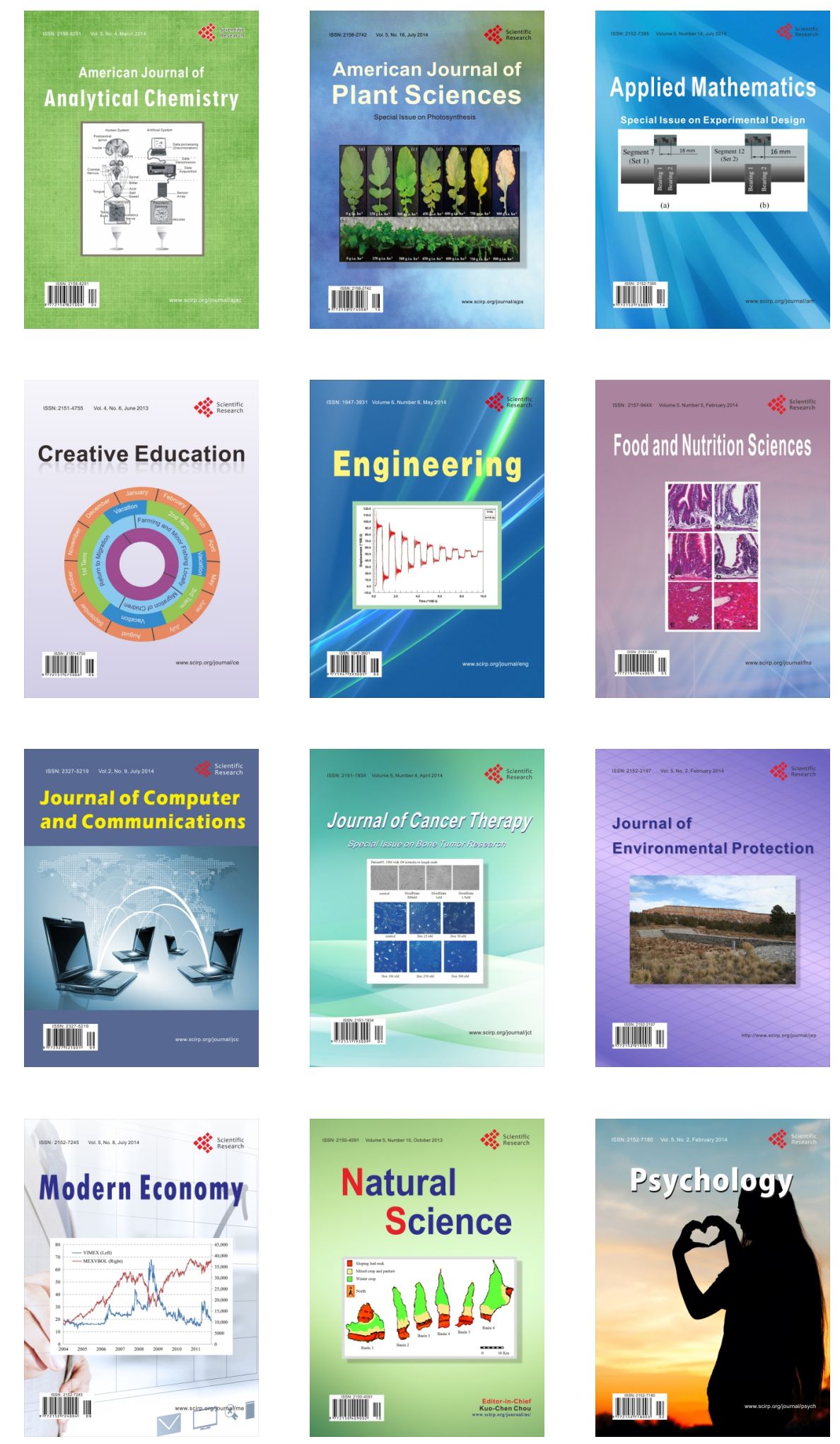